\title{
Microclimate and Thermal Comfort of Urban Forms and Canyons in Traditional and Modern Residential Fabrics in Bandar Abbas, Iran
}

\author{
Masoud Dalman \& Elias Salleh \\ Faculty of Design and Architecture, Universiti Putra Malaysia \\ 43400 Serdang, Selangor, Malaysia
}

Abdul Razak Sapian

Department of Architecture, Kulliyyah of Architecture and Environmental Design

International Islamic University Malaysia, P.O. Box 10, 50728 Kuala Lumpur, Malaysia

Osman Mohd Tahir, Kamariah Dola \& Omidreza Saadatian(Corresponding author)

Faculty of Design and Architecture, Universiti Putra Malaysia, 43400 Serdang, Selangor, Malaysia

Tel: 60-17-207-5459_E-mail: omid.saadatian@gmail.com

Received: December 9, 2010

Accepted: January 5, 2011

doi:10.5539/mas.v5n2p43

\begin{abstract}
Rapid growth of urban population and urban area during the past 30 years in Bandar Abbas city with hot and humid climate has been regarded as the major concern of urban designers and planners. In modern fabric climate response urban design has been ignored. This paper investigates the microclimate principals of two different fabrics in South East of Bandar Abbas using different thermal comfort indices and microclimate assessment of residential urban canyons. Fieldwork studies in two different fabrics indicate that traditional fabric of study area can have good potential to be called a thermal comfort environment if its vegetation and building environment is modified and integrated in the design appropriately. The finding can be used as reference for urban planners and urban designers and municipality experts of the cities which posses the same climate.
\end{abstract}

Keywords: Urban microclimate, Thermal comfort, Urban canyon, Hot and humid climate

\section{Introduction}

The history of Bandar Abbas could be traced back to 400 years ago. Bandar Abbas is a major port of the mouth of the Persian Gulf with a long history of trade and fishing. It is the provincial capital of Hormuzgan (See Figure1). The city has a strategic position on the narrow Straits of Hormuz, and it houses main base of the Iranian Navy. The city is an extremely important trading port and has also attracted industrial investment. The population of Bandar Abbas has increased from 87,000 in 1977 to 273,000 in 1996 and is estimated to be close to 500,000 people in 2010(Alaedini, 2008). Like many other cities, Bandar Abbas has experienced an unprecedented population boom in the last 20 years.

The city possess some small creeks, known as Khoor, which are located in urban area, which are the flows of north part of the city that pours into the Persian Gulf. These Khoors function as drainage systems for flash floods as well as sewages of residential districts. Besides, it divides the urban area in big quarters which have special effects on urban planning of the city (See Figure2).

Bandar Abbas is the largest and the most developed port of Iran (Imam Reza (A.S.)Network, 1999).Since 1980 Bandar Abbas has been rapidly developed as an import and export pole of oil, steel and aluminum industries, as well as ship construction and port services. Moreover, it is regarded as a centre of service industry and tourism. It hence causes a rapid increase in population by attracting more workers which leads to the development of a national class city called Bandar Abbas, as the biggest city in the entire cities of south of Iran. This population increase causes high demand for quick housing which sometimes ignorant of local climate and traditional architecture, especially, in most of the modern and commercial contexts that are covered by high and medium rise buildings. These attributes have an intense effect on the use of energy in buildings, outdoor thermal comfort and urban air quality. 
The urban microclimates are characterized by environmental conditions that are different from those of the surrounding rural and suburban regions (Balázs, 2009). Even though urban area can be warmer than their surroundings due to concentration of pollutant materials, heat resources and high absorption of solar radiation, sometimes they are cooler than rural areas because of buildings geometry, shading effects and material properties of the built forms (Balázs, 2009).

\subsection{Climate}

Iran possesses various climate based on the specific geographical locations. Among those regional climatic, hot and humid regions, which has long summers and short moderate winters lies along a narrow and long coast of Persian Gulf and Oman Sea. The length of area is approximately 2000 kilometers (Shohouhian, 2005). In this region, relative humidity and temperature are high during the critical summer months. Besides, the diurnal temperature difference is rather low in this part of Iran as compared to those for inland regions of the country (Heidari, 2002). This city is located at the hot and humid region which lies at an altitude of $10 \mathrm{~m}$ above sea level at latitude of $27^{\circ} 11^{\prime} \mathrm{N}$ and a longitude $56^{\circ} 22^{\prime} \mathrm{E}$. It has been regarded as the city which has eight months time of harsh conditions of heat (Thapar, 2008).

Shohouhian and Soflaee (2005) have summarized the climatic specification of South of Iran as follow (Shohouhian, 2005):

1. Very low level of annual rainfall with the highest degree of precipitation during autumn and winter;

2. Significantly high humidity in air throughout the year;

3. Weather changing from very hot and humid in summers to moderate in winters;

4. Negligible difference in temperature form day to night;

5. Salty or briny ground water in most areas;

6. Negligible grass and plant covering.

The annual cycle of Bandar Abbas is divided into three major periods as follow:

1) - a moderate weather period from December to March which has daily mean outdoor air temperature of $18-23^{\circ} \mathrm{C}$;

2)- a warm period in November and April which has daily mean outdoor air temperature of $24-27^{\circ} \mathrm{C}$;

3) - a very hot and humid period from May to October with average temperatures of $30-34.5^{\circ} \mathrm{C}$ (See Figure 3 ).

The first and second periods could be considered as comfortable and pleasant. During these two periods, indoor spaces will be considered thermally comfortable if passive techniques are employed. Meanwhile, outdoor spaces will be thermally comfortable if it is shaded well and exposes to the breeze of the Persian Gulf (Thapar, 2008).

Maintaining thermal comfort conditions during the hot period is more challenging compared to the two other periods. Intensifying temperature by a high incident of solar radiation as well as high levels of absolute and relative humidity at certain times of day causes the thermal discomfort for outdoor and indoor spaces during the hot period. The potential of evaporative cooling could be one of the best solutions in order to achieve thermal comfort but this might also be quite limited at the highest level of hot and humid period (Thapar, 2008).Nevertheless, current study assumes that there is a good potential for nocturnal radiative cooling throughout the year and the mean wind speed exceeding $6.0 \mathrm{~m} / \mathrm{s}$ assists to provide comfort in outdoor spaces. The direction of prevailing wind as illustrated in Bandar Abbas wind rose is southward; therefore the streets and allies that are exposed to sea breezes with South-North direction have less humidity and are more comfortable for pedestrians in certain time of day with shaded sidewalks (See Figure 4).

\subsection{Architectural Form}

There are two predominant climatic factors of hot and humid region of Iran that influence the region's architecture, namely; solar radiation and humidity (Azari NajafAbadi, 2006). Therefore, vernacular architectural forms, employs shading and air circulation to increase thermal comfort (Ghobadian, 1998). Iranian vernacular architecture, in this region, employs semi-consolidate urban textures in urban planning, i.e. narrow bindings or spiral-shaped lanes with high walls, to provide shade in hot seasons. Moreover, traditional forms uses thick walls in the central court yard, broad verandas with high canopies, wind towers, upper windows and locally-made materials like coral slates, sedimentary rocks, mud plastering, wood, lumber, reed, and adobe. That indicates the architects who have designed such buildings understood the thermal comfort conditions. Besides, seasonal uses of spaces and effective use of roofs at nights are appropriate solutions for planning in hot and humid climate (Shohouhian, 2005). 
In this region urban texture has semi consolidated form and is bound to south and south east. Urban spaces are half-circled, and cities are mainly developed towards the coast line and have seaward orientation. In the meantime, circular and close forms of urban spaces increase as they get far from the sea coast (Azari NajafAbadi, 2006).

In this region the urban setting is designed to allow air to circulate through urban canyons as well as using tall buildings and vegetations for reducing the heat by shading effect (Dalman, 1992). Consequently, the general orientation of the urban setting in this region follows the directions of coastline and wind; i.e., the streets and paths are arranged in order to catch the pleasant winds coming from the sea (Dalman, 1992).

\subsection{Built Form and Microclimate}

There are three types of built form in Bandar Abbas urban area: high rise towers, mid- rise blocks and low-rise compact courtyard houses. The various forms have strong effects on the urban microclimate and consequently on thermal comfort. Those alter the solar radiation, air movements as well as temperature and shading effects (Thapar, 2008). In recent years of urban development, the high rise buildings have become popular in terms of their advantages of low maintenance, good view, as well as privacy and luxury. Nevertheless, the mid-rise urban blocks are still considered the most popular and finally, the low-rise compact courtyard houses and blocks which mostly conforms vernacular and traditional forms look to be a proper form for climatic conditions. Each form has particular effect on climatic and environmental elements of urban conditions and consequently on boundary layer, urban heat island and thermal specifications of occupied area at ground level (Toudert, 2006). One of the specific effects is distinction in shading level according to geometry, built volume and height of the built forms. It shows the potential of low-rise blocks and compact areas to supply well shading streets for pedestrians.

In the most part of Bandar Abbas, houses have a reasonable size. The average and median size of plots are 204 and $160 \mathrm{~m}^{2}$. Plots measuring $100 \mathrm{~m}^{2}$ or less make up only $18 \%$ of residential dwellings. The average and median size of the buildings are 123 and $100 \mathrm{~m}^{2}$ respectively. The average and median size of free land, i.e. yard and court yard, within existing residential units are 79 and $50 \mathrm{~m}^{2}$ respectively. These open spaces can allow for refurbishing and improvement efforts or in the construction of multi-unit complexes. Meanwhile, $70 \%$ of housing units in these communities are single units with yards and approximately $25 \%$ are attached single units (Alaedini, 2007).

Unattached single units with yards serve dual purposes of importance:

1) They allow the flow of air reducing humidity;

2) They reduce damages from earthquakes, an important point, since the region is earthquake prone. The walls and roofs of these units are constructed from solid and long lasting materials (cinderblocks and cement).

Nevertheless, it should be noted that these structures do not meet minimum building code standards in order of earthquake risk and other environmental concerns (Alaedini, 2007).

The low-rise blocks in terms of context could be divided into three types namely; Historical, modern and slums (See Figures5 a,b,c). These urban fabrics have specific elements due to their forms. Historical zone contains buildings that form a compact context around twisted and narrow streets and alleys which have a height-to-width ratio of 1:8 and are $1-3{ }^{\circ} \mathrm{C}$ cooler than street canyon which has a 2:1 height- to-width ratio (Alaedini, 2007). The street canyon's rate of height-to-width cause more solar exposures and consequently higher temperature (See Figures 6, 7 and Table 1).

\subsection{Vegetation Layout}

One of the main differences between modern and traditional zones that illustrated in figure 8 is the usage of vegetation which has particular effects on shading and thermal comfort especially when the solar radiation is in higher rate in hot period of days and year. However, greenery and vegetated area are costly to maintain due to dry climate and high cost of desalinization of water. Therefore urban managers have to cultivate xerophytes and native trees to provide enough greenery and shading to reducing holding cost of vegetation (Thapar, 2008). Vegetation and shading of buildings by trees can help reduce usage of energy for air conditioning and in urban scale will improve urban air quality and can provide lower ambient temperature.

\section{Material and Methods}

The main methods used in this study are the calculation of thermal comfort indices such as Physiological Equivalent Temperature (PET), Predicted Mean Vote (PMV), Standard Effective Temperature (SET*) and Mean Radiant Temperature (MRT).The next method is comparative analysis of two typologies of urban canyons and urban forms in selected area of South East of Bandar Abbas near the shorelines through field measurements. 
This study also has tried to analyze the urban canyon characteristics in two different canyons of traditional and modern fabrics through measuring important climatic factors of air temperature, relative humidity and air velocity to observing microclimatic conditions of study area.

\subsection{RayMan Model}

To calculate the relevant thermal comfort indices such as PET, PMV and SET, this study has used RayMan model that has been developed for calculation the thermal comfort indices, human energy fluxes based on the Munich Energy Balance Model for Individuals (MEMI).The mean radiant temperature in simple and complex environments could be calculated by inserting the environmental data (i.e. climatic and physical data), personal data and time and date of study period. Calculations of human body parameters are also included. This Model has developed to study urban climate like calculation of the short and long wave radiation, sun shine duration, shadow, sky view factor and global radiation to use in study of urban topography, structure and vegetation (Matzarakis, 2007).

\subsection{Thermal Comfort Indices}

The main thermal comfort indices used in this study were:

1) Predicted Mean Vote (PMV) which represented the human body's heat equilibrium with regard to the net heat transfer under the impacts of six factors identified by Macpherson (Macpherson, 1973; Fanger, 1970). The general comfort equation is as follows (Macpherson, 1973).

$P M V=[0,303 \cdot \exp (-0,036 \cdot M)+0,028] L$, Where:

- $\quad \mathrm{PMV}=$ Predicted Mean Vote, or thermal comfort analytical sensation (a dimensional)

- $\mathrm{M}=$ Metabolic heat production $\operatorname{tax}\left(\mathrm{W} / \mathrm{m}^{2}\right)$

- $\mathrm{L}=$ Thermal load actuating over the body $\left(\mathrm{W} / \mathrm{m}^{2}\right)$

2) The next comfort index is Physiological Equivalent Temperature (PET) which is based on the Munich Energy-balance Model for Individuals (MEMI) (Höppe, 1999).

Table 2shows the Comparison of PMV and PET ranges for different human sensations and thermal stress level by human beings, (Internal heat production: $80 \mathrm{~W}$, heat transfer resistance of the clothing: $0.9 \mathrm{clo}$ ), (Matzarakis, 1999).

3) SET* index is similar to PMV and used by the American Society of Heating, Refrigerating and Air-Conditioning Engineers (ASHRAE). SET* compares individual physiological comfort to a reference environment with a temperature equal to the mean radiant temperature (Tmrt) in the ambient environment, wind velocity of zero, at sea level (Ye, 2003). SET* allows thermal comparisons between environments at any combination of the physical input variables (Matzarakis, 1999).

4) MRT is the area weighted mean temperature of all the objects surrounding the body. Technically, MRT is defined as the uniform temperature of a surrounding surface giving off blackbody radiation (emissivity e $=1$ ) which results in the same radiation energy gain on a human body as the prevailing radiation fluxes which are usually very varied under open space conditions. MRT is the most important parameter governing human energy balance, especially on hot sunny days (Wikipedia, 2010). MRT also has the strongest influence on thermo physiological comfort indexes such as PET or PMV.

\subsection{Comparative Analysis}

To understand the influences of urban forms and layout on microclimate and thermal comfort of study area, a comparative investigation was taken in two typologies of Bandar Abbas urban area. Measurements which were taken in the urban environment are dealt with careful and detailed procedure. Given that results might vary greatly, both between and within different parts of a city, it is rarely easy to draw meaningful comparisons. Thus comparability was a key criterion in the selection of sites for the measurements taken in study area in July 2009. Two representative areas were selected for measurements and thermal comfort surveys and these result.

The selected areas were located near sea shore. Two different fabrics separated by a street in South east of Bandar Abbas as shown in figure 9. The main goal of selecting this area was that, this area was the best and the only place in city that traditional and modern fabric were near to each other with similar microclimate, similar location, similar distance to sea shore, same influence of sea breeze and finally was mainly covered with courtyard and single story houses. The traditional fabric is called Nakhl-e-Nakhoda (Captain Palm) and new 
residential development is called South Golshahr. Two spots were, subsequently, selected in each area for the measurements at three days of July 15 to July 17 which were hottest period of year.

Measurements in each location included records of air temperatures, relative humidity, and wind speed at interval of one hour. A thermal comfort survey was undertaken involving PET, PMV and SET comparatively. Measurements were carried out with Lambrecht meteorological instruments installed at selected points (See Figure10).

\subsection{Measuring and Observing Climate Condition}

The highest temperature and relative humidity recorded during the period of measurment (15-17 July 2009) at the refrence met station set for this fieldwork was $39.4{ }^{\circ} \mathrm{C}$ and $94 \%$ in modern fabric and $38.4{ }^{\circ} \mathrm{C}$ and $92 \%$ in tradiotional fabic(See Figure11).

The mean air temperature for the measuring period was $35{ }^{\circ} \mathrm{C}$ and the maximum $39.4{ }^{\circ} \mathrm{C}$ (at $15 \mathrm{pm}$ on the 16 th July). After sunset air temperatures dropped slowly to minima around $32.2{ }^{\circ} \mathrm{C}$. The relative humidity was in the range of $55-94 \%$ for the measurements period. Owing to the high air temperatures, the peak values of relative humidity represent fairly high levels of absolute humidity. The maxima of $94 \%$ (at 02.00 am on the 17th July) recorded on the last day of measurements correspond to a moisture content of $33.7 \mathrm{~g} / \mathrm{m}^{3}$ dry air. The lowest $\mathrm{RH}$ value of $55 \%$ (at $19.00 \mathrm{pm}$ on 15 th July) corresponds to a moisture content of $25.2 \mathrm{~g} / \mathrm{m}^{3}$ dry air..

Throughout the recording period relative humidity levels were lowest around mid-morning at which time the weather conditions felt dry, whereas later in the day the high humidity values caused discomfort. This variation indicates there may be scope for evaporative cooling during the morning hours to cool the air for later use.

Wind velocities of up to $7 \mathrm{~m} / \mathrm{s}$ were measured in open areas (Airport weather station), (IMO, 2010) throughout the fieldwork period. These were welcomed by peoples throughout the day while air temperatures were as high as $38^{\circ} \mathrm{C}$. But in residential canyons wind velocity measured around $1.3 \mathrm{~m} / \mathrm{s}$ in traditional fabric (at $14 \mathrm{pm}$ on the 15 July) and $0.9 \mathrm{~m} / \mathrm{s}$ in modern fabric (at $15 \mathrm{pm}$ on the 15 July).

\subsection{Urban Canyon Analysis}

The main focus of this part is to describe the details of selected urban canyons and particularities of these canyons regarding to physical, microclimate and thermal comfort specifications of two prevailing typologies of selected traditional and modern fabrics of residential districts. The canyon analysis indicates on diversities of measured weather factors and reasons of these changes particularly in order to wind and thermal comfort characteristics.

\subsubsection{South Golshahr}

Starting from the middle of 80 's to build up by private owners, mainly one story houses. After year of 2000 especially the street sides of area built as commercial and residential medium and high rise buildings. In recent 10 years, interior empty areas also started to construction in multi story buildings. The selected canyon in modern fabric has a Height-to-Width Ratio $(\mathrm{H} / \mathrm{W})$ of 0.5 and located in court yard area of modern fabric. The direction of canyon is WSW-ENE unlike the selected canyon of traditional fabric with N-S direction, therefore has a little benefit of sea breezes. In modern area the temperature and relative humidity is slightly higher than the older fabric and also air movement in N-S canyon is higher than those recorded in WSW-ENE canyon (See Figure12 a, b).

The highest temperature and relative humidity recorded during the measurement period were $39.4{ }^{\circ} \mathrm{C}$ and $94 \%$, compared with recorded data of reference station $\left(38^{\circ} \mathrm{C}\right.$ and $\left.82 \%\right)$ are slightly higher, owing to the differences of wind speed, which is $0.0 \mathrm{~m} / \mathrm{s}$ in modern fabric and $2.0 \mathrm{~m} / \mathrm{s}$ in reference station.

\subsubsection{Nakhl-e-Nakhoda}

The history of this quarter back to a separated fisherman's village, $8 \mathrm{~km}$ away from Bandar Abbas historical city center in more than two hundred years ago. During recent 40 years and rapid development of urban areas especially in 1980's have, has included to urban area but still has traditional form and in eastern and northern part of this fabric, illegal houses are built during recent 20 years (Alaedini, 2008).

This fabric has developed along the sea shoreline and selected canyons are belonging to traditional forms with narrow lanes and sandy pathways and mainly North-South direction.

As figure 11 shows registered data of temperature and relative humidity in traditional area significantly are lower than modern fabric while wind speed is higher also the highest recorded $\mathrm{Ta}$ and $\mathrm{RH} \%$ are $38.6^{\circ} \mathrm{C}$ and $92 \%$, 
slightly lower than modern fabric, owing to more shading achieved to the ground and higher wind speed because of exposure to sea breezes.

The recorded wind speed in Figure 13 shows that the wind has blew between 10am to 8pm in traditional fabric with higher speed as $1.3 \mathrm{~m} / \mathrm{s}$, in same time in modern fabric from $10 \mathrm{am}$ to $10 \mathrm{pm}$ higher speed of $0.9 \mathrm{~m} / \mathrm{s}$ has been registered. From $9 \mathrm{pm}$ to next day $10 \mathrm{am}$ the wind speed was $0.0 \mathrm{~m} / \mathrm{s}$ owing to replacing of sea breezes direction during nights from land to sea and also hindering effects of buildings. Recorded wind at reference station during measuring period shows wind speed during nights between $2-6 \mathrm{~m} / \mathrm{s}$ in open spaces.

\section{Result and Discussion}

This study investigated human thermal comfort conducted on a typical summer three days in 2009 for two types of urban residential canyons. The computation of PET and PMV by using Ray Man model in table3 shows that the old fabric has more comfortable situation than the modern one. But still in hot period of year and sample day, the comfort situation is unsatisfied for occupants, and routine activities are faced with more difficulties in both fabrics. Recorded and calculated values of thermal comfort indices revealed that it is very difficult to reach thermal comfort passively in a region with hot and humid climate (See Figure15). The amount of Thermal comfort indices in table 4 shows the major incline and decline hours with higher and lower values of Ta, $\mathrm{RH} \%$ and wind variations.

Increasing the amount of vegetation and consequently more shading and also higher aspect ratio $\mathrm{H} / \mathrm{W}$ and North-South street orientation can cause better comfort time during days. Increasing the aspect ratio can be a better strategy to improve thermal comfort for both E-W and N-S orientations, although the N-S canyons still provide better thermal comfort for dwellers (Shohouhian, 2005) (See Figure14(a and b).

The results also indicate the noticeable role of solar radiation and sun exposure, showed by mean radiant temperature (Tmrt) under hot conditions, therefore pedestrian absorb energy from surrounding surfaces and from a direct exposure of his body. This is the main reason of shading need in urban canyons in hot period of summer days (Toudert, 2006). According to Bandar Abbas latitude e.g. $27^{\circ} \mathrm{N}$, the solar radiation in summer period reach to peak around 86 degree. The recorded wind, relative humidity and air temperature in measuring period in both fabrics by different orientation and geometries shows these factors are in second degree to influencing human thermal comfort since it is moderately affected by canyon geometry changes (Mayer, 2008). This study represents the basis for the development of human thermal comfort and provides new strategies to mitigate thermal stress in different urban quarters in hot and humid summer climate.

\section{Conclusion}

The result indicates remarkable differences of building layout between the traditional fabric and modern fabric of the old area and new residential developments. The study finding asserts three important following statements:

1-Canyon Orientation was found out to be the first contributor of thermal comfort in the selected area whereby causes proper shading condition and conducive ventilation. In this regard, prevailing wind, and sea breeze in conjunction of canyon orientation functions significantly in providing a thermally comfortable situation. Since $\mathrm{H} / \mathrm{W}$ ratio in traditional fabrics is higher than modern fabric therefore, the traditional fabric was found out to be more thermally comfortable than the modern fabric. Hence, there is a lack of proper consideration in embedding the shading and ventilation factors in design process in modern fabrics of Bandar Abbas.

2- Vegetation was revealed to have a positive effect in providing cooling benefits particularly during daytimes, when there is a high altitude of sun with high solar radiation in summer. Based on the study finding, the traditional fabric has more conducive vegetation layout rather than modern fabric in terms of thermal comfort.

3- According to investigations of microclimate situation and computation of thermal comfort indices (PET, PMV, SET*), it was found out providing a thermal comfort condition relying solely on passive techniques is almost impossible for the peak heat of summer. However, utilizing passive techniques can relief thermal stress in specific hours such as morning in shaded areas and at night.

The calculated values of thermal comfort indices show higher ratio in modern fabrics than traditional area, this is the effect of lower $\mathrm{H} / \mathrm{W}$ ratio and inadequate wind circulation and shading.

Therefore there is a need to device: 1- higher $\mathrm{H} / \mathrm{W}$ ratio 2- increasing vegetation cover and 3- considering urban canyon orientation according to prevailing wind in design process of new development areas. It is recommended Iranian legislation organizations or Bandar Abbas municipality enforces the developers to follow the mentioned consideration by providing a set of regulations. 


\section{References}

Alaedini, P. et al. (2007). Land market and housing dynamics in low income settlement in Iran: Examining data from three cities, 2007, World Bank/Government of Iran, Urban upgrading and housing reform project (UUHRP).

Imam Reza(A.S.). (1999).Network. Iran at a Glance. 1999 [cited 2008 1/07/2008]; Available from: http://www.imamreza.net/eng/imamreza.php?id=2130\&page=9.

Balazs, B. et al. (2009). Intensive observation Period for the study of microclimate in a high-rise residential development in Singapore. 2009, Singapore National Research Foundation: Singapore.

Shohouhian, et al. (2005). Environmental sustainable Iranian traditional architecture in hot-humid regions. in International sustainable "Passive and Low Energy Cooling for the built Environment". 2005. Santorini,Greece.

Heidari, S. and S. Sharples, (2002). A comparative analysis of short-term and long-term thermal comfort surveys in Iran. Energy and Buildings, 2002. 34(6): p. 607-614.

Harsh Thapar*, S.Y. (2008). Microclimate and urban form in Dubai, in PLEA 2008 - 25th Conference on Passive and Low Energy Architecture, Dublin, 22nd to 24th October 2008. 2008, Environment \& Energy Studies Programme: Dublin.

Azari, R., et al. (2006). Role of wind in vernacular architecture of hot and humid region of Iran, in Fifteenth Symposium on Improving Building Systems in Hot and Humid Climates. 2006: Orlando, FL.

Ghobadian, V. (1998). Climatic survey of traditional buildings of Iran. 1998, Tehran: Tehran University Press.

Dalman, M. (1992). A Bioclimatic study on the Architectural elements of Southern Coastal cities of Iran (case study of Bandar Abbas), Department of Geography. 1992, University of Isfahan: Isfahan.

Fazial Ali-Toudert, H.M. (2006). Effects of street design on outdoor thermal comfort. 2006.

Matzarakis, A., et al. (2007). Modeling radiation fluxes in simple and complex environments - Application of the RayMan model. International Journal of Biometeorology, 2007, 51: p. 323-334.

Macpherson, R. (1973). Thermal stress and thermal comfort. Ergonomics.1973. 16(5): p. 611-622.

Fanger, P.O. (1970). Thermal comfort, analysis and application in environmental engineering. 1970: McGrawHill.

Höppe, P. (1999). The physiological equivalent temperature - a universal index for the biometeorological assessment of the thermal environment. Int J Biometeorological, 1999(43): p. 71-75.

Matzarakis, A., et al. (1999). Applications of a universal thermal index Physiological equivalent temperature. Int J Biometeorological, 1999(43): p. 76-84.

Ye, G., et al. (2003). A new approach for measuring predicted mean vote and standard effective temperature. Building and Environment, 2003(38): p. 33-44.

Wikipedia. (2010). Mean radiant Temperature (Tmrt). Available on: http://en.wikipedia.org/wiki/Mean Radiant Temperature.

Meteorological office of Hormozgan province, Meteorological information of Bandar Abbas. 2008.

Mayer, H. et al. (2008). Human thermal comfort in summer within an urban street canyon in Central Europe. Meteorologische Zeitschrift, 2008. Vol. 17(No. 3): p. 241-250.

Table 1. Inventory of street canyons

\begin{tabular}{|l|l|l|l|l|l|l|l|l|}
\hline Site & $\begin{array}{l}\text { Type of } \\
\text { Canyon }\end{array}$ & $\begin{array}{l}\text { H/W } \\
\text { Ratio }\end{array}$ & Orientation & $\begin{array}{l}\text { Vehicle } \\
\text { Traffic }\end{array}$ & $\begin{array}{l}\text { Ground } \\
\text { Cover }\end{array}$ & $\begin{array}{l}\text { Distance } \\
\text { from } \\
\text { Sea(m) }\end{array}$ & $\begin{array}{l}\text { Distance } \\
\text { between } \\
\text { Two } \\
\text { Site(m) }\end{array}$ & $\begin{array}{l}\text { Fabric } \\
\text { specification }\end{array}$ \\
\cline { 1 - 6 } South Golshahr(M) & Residential & 0.5 & WSW-ENE & Medium & Asphalted & 438 & \multirow{2}{*}{955} & $\begin{array}{l}\text { New } \\
\text { Development }\end{array}$ \\
\cline { 1 - 5 } Nakhl-e-Nakhoda(T) & Residential & 1.0 & N-S & Low & Sandy & 380 & Traditional \\
\hline
\end{tabular}


Table 2. Comparison of PMV and PET ranges for different human sensation and thermal stress level by human beings(Source: Matzarakis et al 1999)

\begin{tabular}{|c|c|c|c|}
\hline PET $\left({ }^{\circ} \mathrm{C}\right)$ & PMV & Human sensation & Thermal stress level \\
\hline 4 & $\ldots \ldots$ & very cold & extreme cold stress \\
8 & -3 & cold & strong cold stress \\
13 & -2 & cool & moderate cold stress \\
18 & -1 & slightly cool & slight cold stress \\
23 & 0 & comfortable & no thermal stress \\
29 & 1 & slightly warm & slight heat stress \\
35 & 2 & warm & moderate heat stress \\
41 & 3 & hot & strong heat stress \\
\hline & & very hot & extreme heat stress \\
\hline
\end{tabular}

Table 3. Thermal comfort indices calculated using RayMan Model

\begin{tabular}{|c|c|c|c|c|c|c|c|c|}
\hline \multirow{2}{*}{ Hour } & \multicolumn{2}{|c|}{$\operatorname{PET}\left({ }^{\circ} \mathbf{C}\right)$} & \multicolumn{2}{|c|}{ PMV } & \multicolumn{2}{|c|}{$\operatorname{SET}^{*}\left({ }^{\circ} \mathrm{C}\right)$} & \multicolumn{2}{|c|}{$\operatorname{Tmrt}\left({ }^{\circ} \mathrm{C}\right)$} \\
\hline & TRD & MDR & TRD & MDR & TRD & MDR & TRD & MDR \\
\hline 06 & 32.7 & 32.2 & 2.5 & 2.4 & 27 & 26.5 & 31 & 30.4 \\
\hline 10 & 57.3 & 60.6 & 8.2 & 8.3 & 50.9 & 51.6 & 70.2 & 71.2 \\
\hline 14 & 53.7 & 56.3 & 7.3 & 7.8 & 46.6 & 49.6 & 68.5 & 70.4 \\
\hline 18 & 35.7 & 36.1 & 3.3 & 3.4 & 30.1 & 30.3 & 34.1 & 34.4 \\
\hline 24 & 28.9 & 29.1 & 1.8 & 1.9 & 23.4 & 23.6 & 23.8 & 24 \\
\hline
\end{tabular}

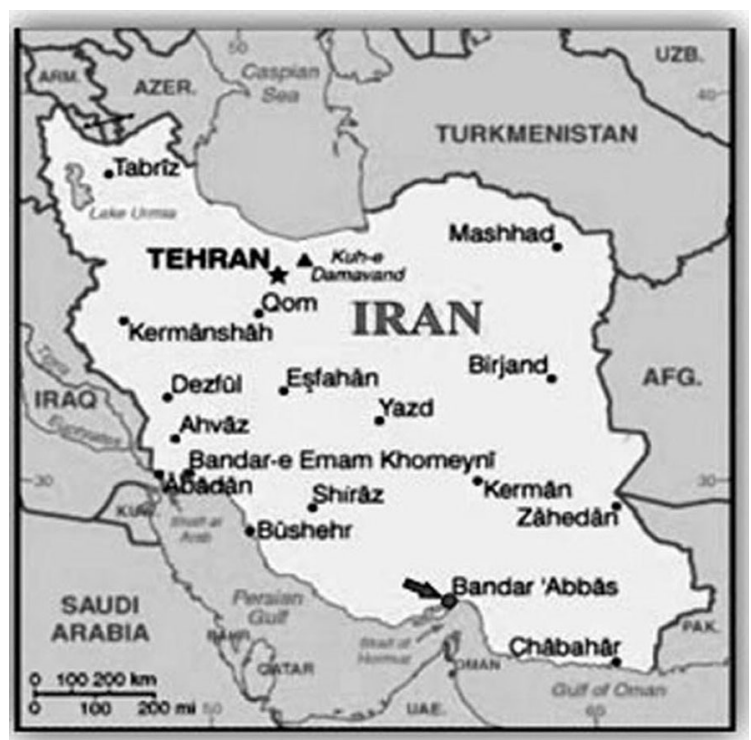

Figure 1. Location of Bandar Abbas in country 


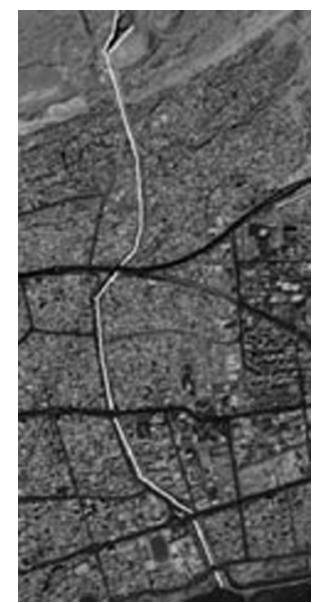

Figure 2. One of the biggest Creek in Bandar Abbas (Gorsoozan Khoor)

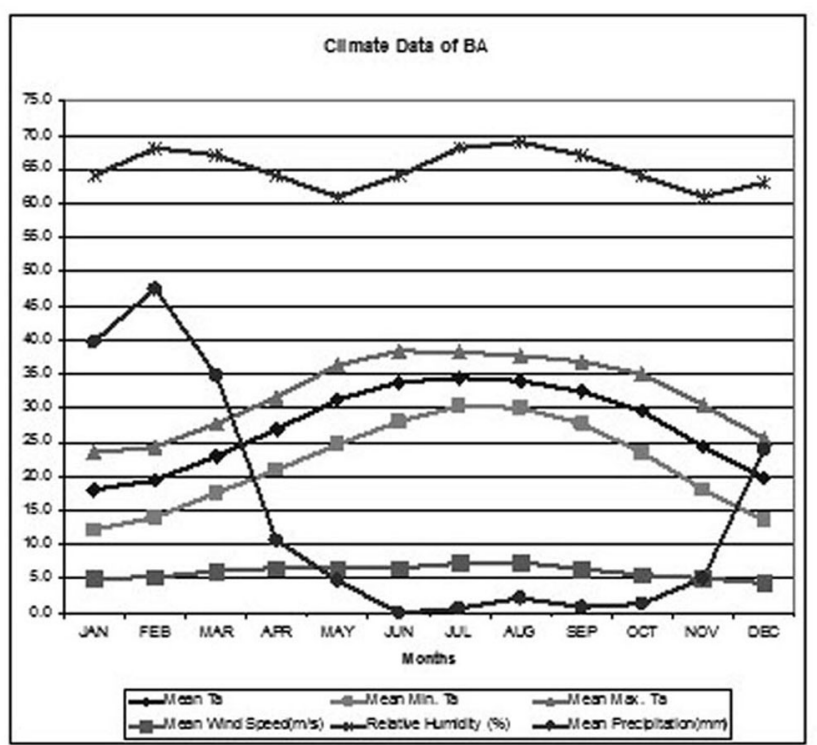

Figure 3. Climate chart of B.A,

(Source: Meteorological Office of Hormozgan Province 2008) [8] 


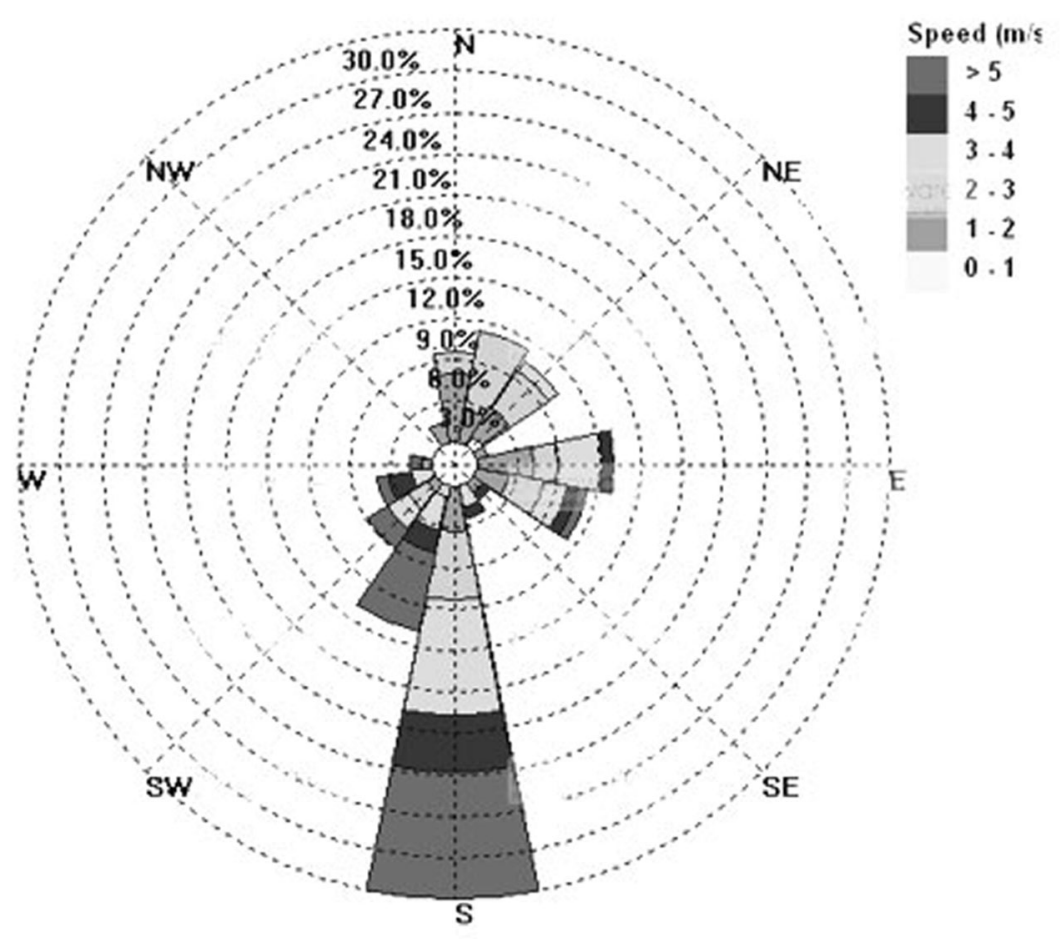

Figure 4.Wind Rose of 14-18 July 2009-(Bandar Abbas)
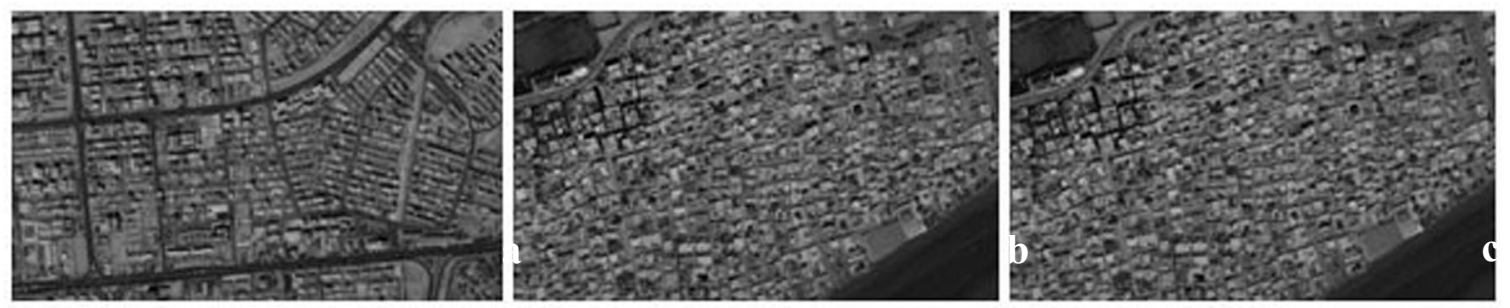

Figure 5. New development (a), Historical (b) and Slum(c) Fabrics

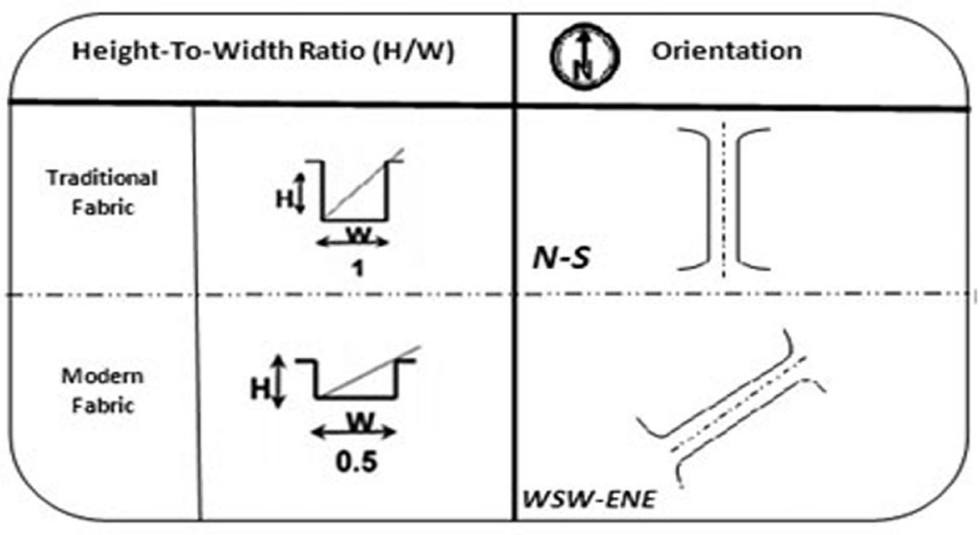

Figure $6 . \mathrm{H} / \mathrm{W}$ ratio and orientation of selected canyons 

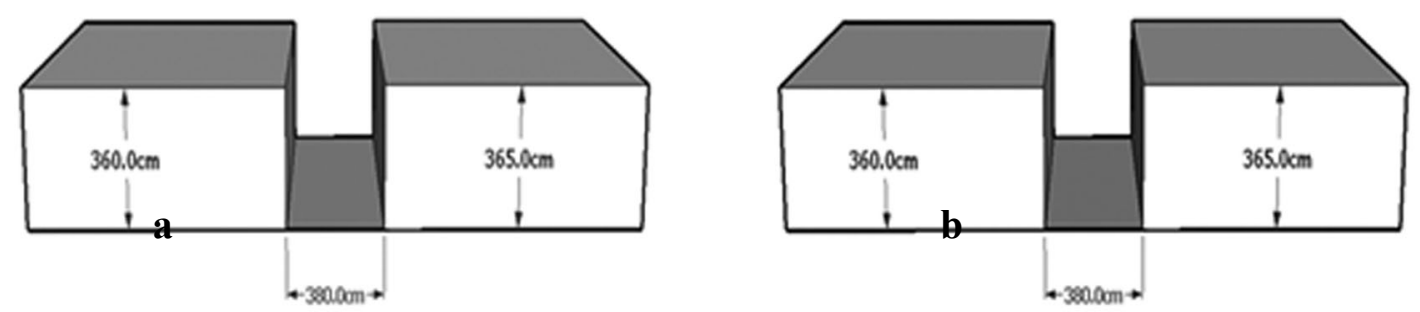

Figure 7. Canyon section in both traditional (a) and modern (b) fabrics

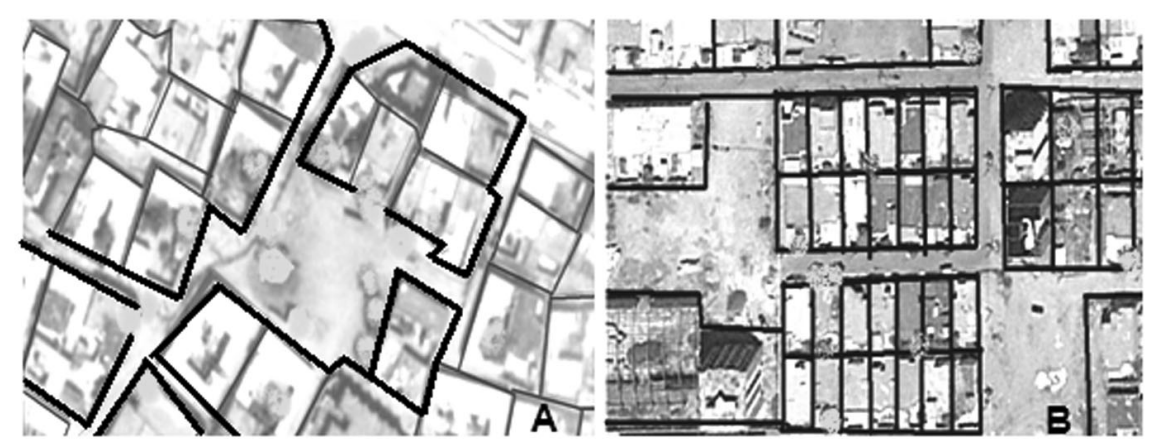

Figure 8. Vegetation4 layout in Traditional (A) and new residential development (B)
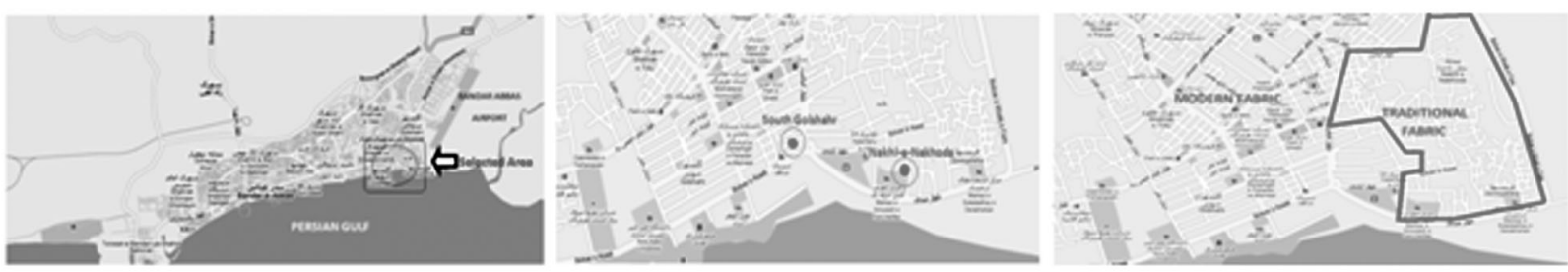

Figure 9. The schematic process of selecting location of study area in south east of Bandar Abbas
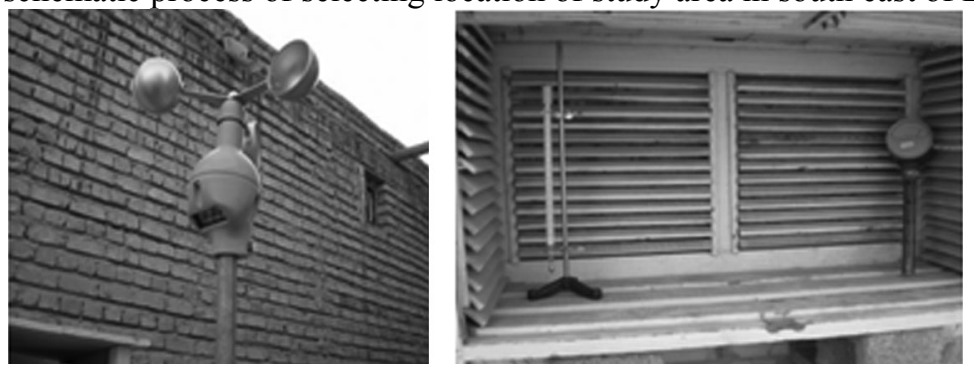

Figure 10. Meteorological instruments used in measurements 

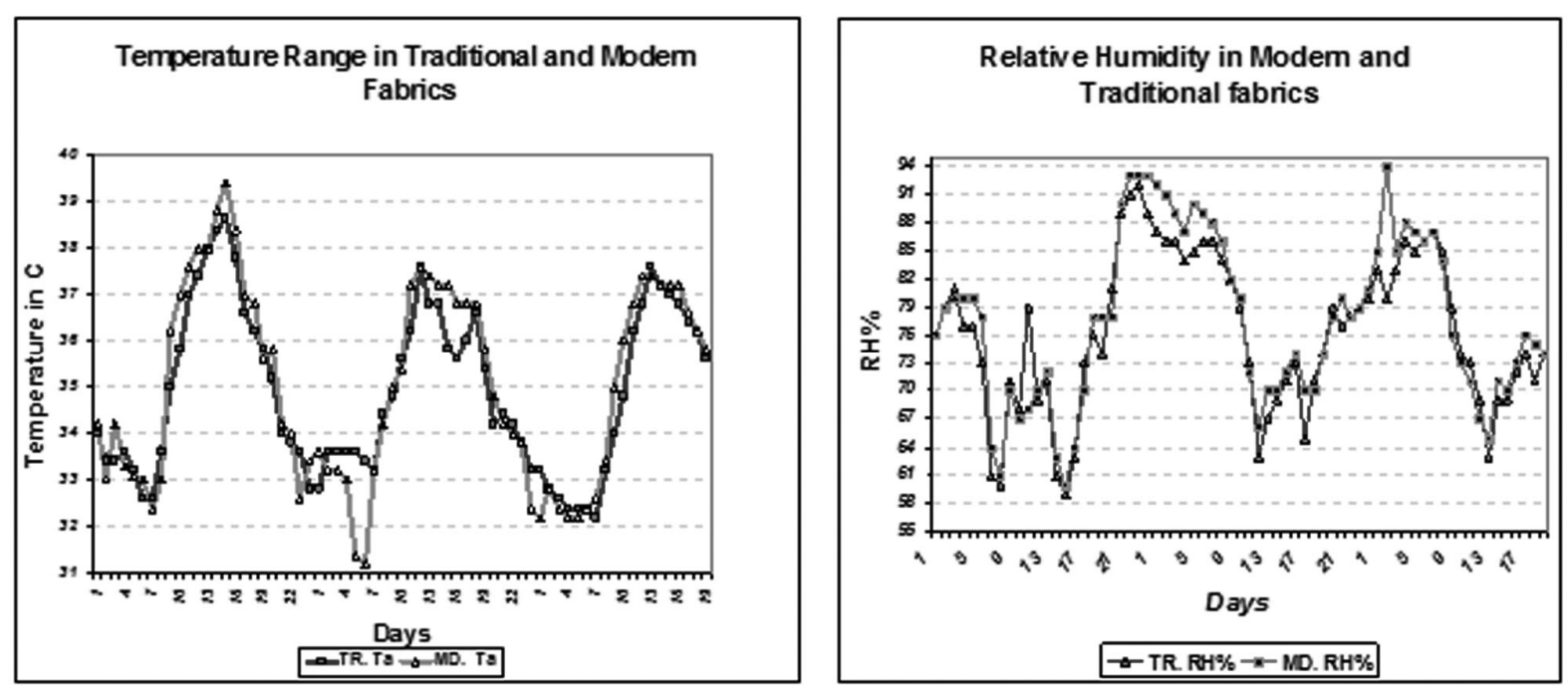

Figure 11. Variation of Ta and $\mathrm{RH} \%$ in diffrent fabrics
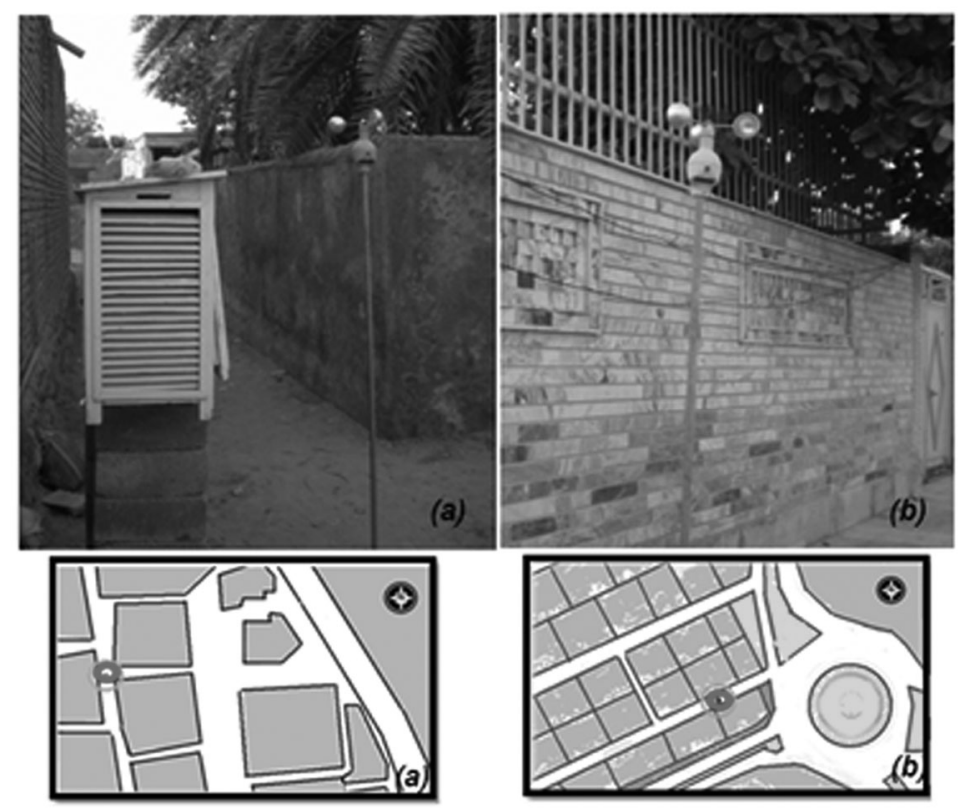

Figure 12. Selected points for measurements in two different fabrics 


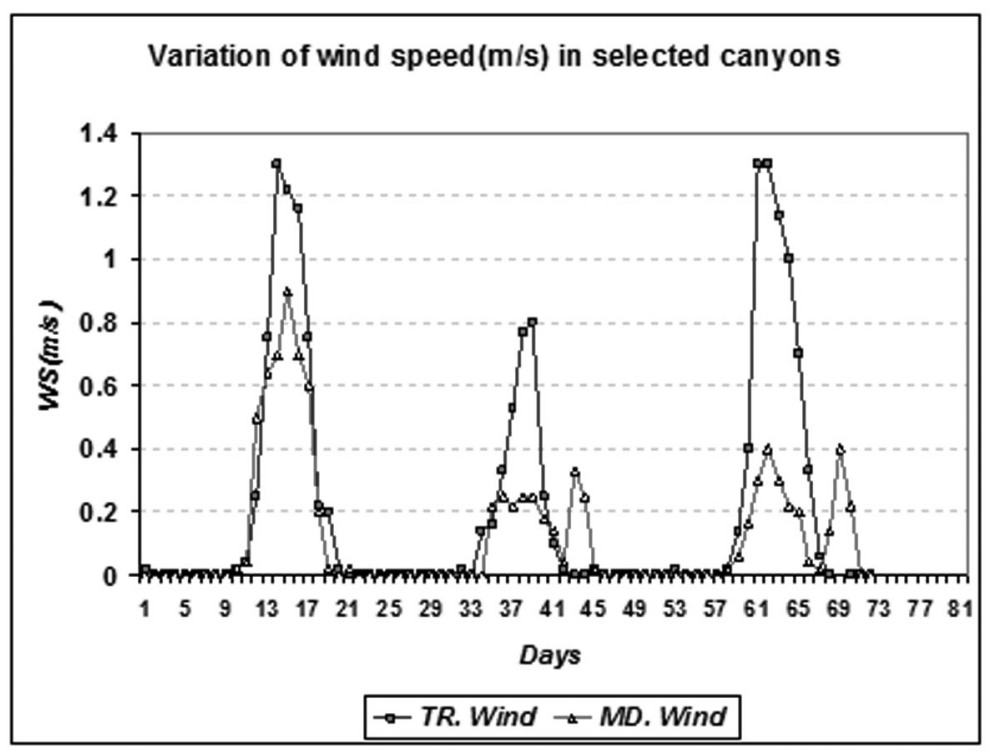

Figure 13. Air movements in two fabrics with different orientations

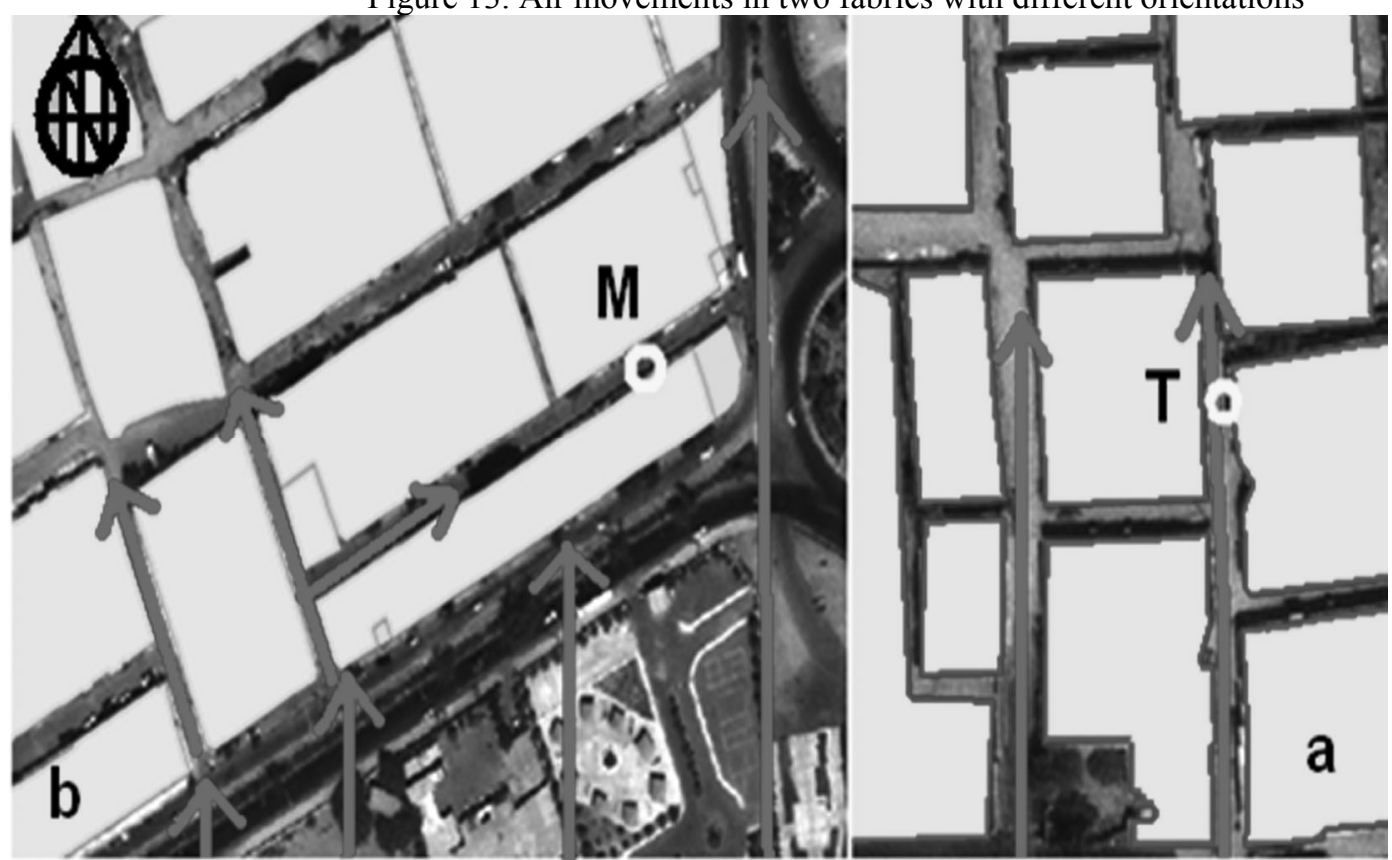

Figure 14. Prevaling wind and different canyons, Traditional(a), Modern(b) 


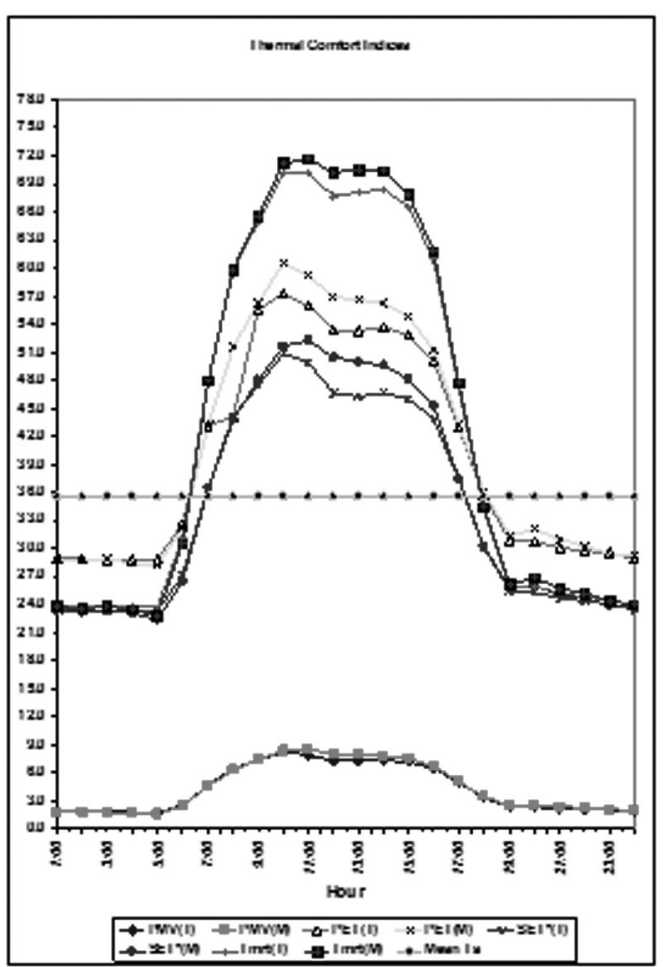

Figure 15. Thermal Comfort Indices in Two Selected Fabrics 